\title{
Laparoscopy and hysteroscopy in patients of infertility in a rural set up
}

\author{
Amogh Chimote*, Swarnalata Samal, Chella Hariharan, Riju Angik
}

\begin{abstract}
Department of Obstetrics and Gynaecology, Acharya Vinoba Bhave Rural Hospital (AVBRH), DMIMS (DU),
\end{abstract} Sawangi (Meghe),Wardha, Maharashtra,India

Received: 02 January 2015

Accepted: 13 February 2015

\section{*Correspondence:}

Dr. Amogh Chimote,

E-mail: amoghdr@yahoo.co.in

Copyright: (c) the author(s), publisher and licensee Medip Academy. This is an open-access article distributed under the terms of the Creative Commons Attribution Non-Commercial License, which permits unrestricted non-commercial use, distribution, and reproduction in any medium, provided the original work is properly cited.

\begin{abstract}
Background: Infertility is a life crisis. The number of couples seeking medical help for infertility is increasing dramatically. The incidence of infertility in any community varies between 5-15\%. This problem is compounded by the trend towards delayed child bearing to achieve socio-economic, educational and professional goals and the rapidly diminishing availability of adoptable infants. These couples are relatively well informed. Diagnostic laparoscopy \& hysteroscopy have emerged as an accurate method of assessing, evaluating and treating infertility. Direct visualization of the abdominal and pelvic organs in laparoscopy allows a definitive diagnosis to be made in many conditions where clinical examination and less invasive techniques such as ultrasound and HSG fail to identify the problem.

Methods: A prospective study conducted in Department of Obstetrics and Gynaecology, JNMC, AVBRH, and DMIMS. 60 women with $\mathrm{H} / \mathrm{O}$ infertility for $\geq 1$ year were enrolled and subjected to diagnostic tests. Cases with diagnosed tubal blockage, active lower genital tract infection, suspected pregnancy, tuberculosis and high risk medical disorders were excluded.

Results: Endometriosis 32\%, ovarian disorder (22\%), Intra uterine synechiae and cervical stenosis together $14 \%$, tubal block (6\%) tubal pathology (delayed spill) $(18 \%)$.

Conclusions: Laparoscopy and hysteroscopy detects pelvic pathology which can appear to be normal on other imaging modalities and provides direct visualization as well as treatment of the diseased condition. Laparoscopy and hysteroscopy combined together are valuable technique for complete assessment of female factors of infertility patient and should be used early in the diagnostic work up in cases of infertility.
\end{abstract}

Keywords: Laparoscopy, Hysteroscopy, Infertility

\section{INTRODUCTION}

Infertility is a life crisis. The number of couples seeking medical help for infertility is increasing dramatically. ${ }^{1}$ The incidence of infertility in any community varies between $5-15 \% .^{2}$ It I s estimated that in India $10-15 \%$ of couples are infertile. ${ }^{3}$

Infertility is regarded as a social stigma, in pursuit of a stable family structure and a social standing there is an increase in demand for diagnostic and therapeutic investigation for management of infertility.
The National Institute for Clinical Excellence (NICE) define infertility as failing to get pregnant after a two years of regular unprotected sex. While WHO (World Health Organization) defines infertility as "a disease of the reproductive system defined by the failure to achieve a clinical pregnancy after 12 months or more of regular unprotected sexual intercourse. ${ }^{3}$

Frequently, problems that cannot be discovered by an external physical examination or other radiological investigations can be discovered by laparoscopy and hysteroscopy, two procedures that provide a direct look at 
the pelvic organs. These procedures may be recommended as part of infertility care, depending on particular situation. Laparoscopy and hysteroscopy can be used for both diagnostic and operative purposes.

The optimal initial infertility investigation protocol is diagnostically accurate, expeditious, cost-effective, dependable, and minimally invasive. The current established diagnostic screening tests for tubal patency are regarded as accurate but having significant disadvantages. $^{5}$

Laparoscopy with chromopertubation is viewed as the "gold standard" test for tubal assessment in many infertility centres. ${ }^{6-8}$ Adding hysteroscopy to the procedure allows for concomitant evaluation of the intrauterine cavity and may identify congenital or endometrial abnormalities. ${ }^{5}$

Although infertility is a global medical problem, affecting an estimated 60-80 million couples, the vast majority of them live in low resource countries. ${ }^{9,10}$ Patients living in rural areas and those with low income find it difficult to seek healthcare for infertility related issues because of the treatment costs, long duration of therapy, frequent visits to the hospital and need to travel long distances for expensive interventions.

The present study is carried out to enhance our knowledge in regards to role of laparoscopy and hysteroscopy as a safe, effective, cost effective and accurate tool for the assessment and planning the protocol for management of infertility. Since this study is carried out in a rural set up in India it will give us an opportunity to compare the pathophysiological nature of infertility amongst the rural population as well as for women in the Indian subcontinent.

\section{Aim}

Diagnostic laparoscopy \& hysteroscopy for patients of infertility (Primary and Secondary) to assess Utero-TuboOvarian factors.

\section{Objectives}

1. To Assess and Analyse Utero-tubo-ovarian abnormalities/anomalies in infertile females.

2. Determine the role of laparoscopy and hysteroscopy as an investigation for patients with infertility.

\section{METHODS}

This was a prospective study of 63 patients with history of primary or secondary infertility selected from OPD of AVBRH Sawangi (Meghe) for a period of 2 years (September 2012 to September 2014). The age group of the patients was between 20 yrs. -35 yrs.

\section{Inclusion criteria}

- Primary infertility

- Secondary infertility

\section{Exclusion criteria}

- Cases with lower genital infection without resolution or treatment

- Cases with suspected pregnancy or active tuberculosis infection.

- High risk medical disorders such as cardiovascular, respiratory or immune disorder were also excluded from the study.

All patients within the inclusion criteria were selected and subjected to detailed history pertaining to Infertility, obstetric carrier, menstrual cycle past, personal and family history along with any treatment history for both male and female. The female partner was subjected to clinical examination right from head to toe examination as well as systemic examination along with local and gynaecological examination. Underwent certain basic blood investigations, ultrasonography (USG) pelvis and husband's semen analysis; and patient was asked to follow-up with next menstrual cycle. Patients selected for laparoscopic, hysteroscopic evaluation were admitted in the post menstrual /pre-ovulatory phase Along with laparoscopy chromopertubation for tubal patency ovarian drilling, adhesiolysis etc. were also done if required. All the data was recorded on a predesigned format. The collected data was compiled and proper statistical formulas.

\section{Statistical analysis}

Statistical analysis was done using Graph Pad Prism.

\section{RESULTS}

The present study include 63 cases of both primary and secondary infertility of which 46 cases (73\%) were primary infertility and 17 cases $(27 \%)$ were secondary infertility (Table 1) indicating a rising trend in the detection rate of infertility at the earliest.

The age group of 20-25 had maximum number of patients in the study (42\%) indicating that there is increasing awareness among the present generation regarding infertility and the requirement for this condition (Table 2).

\section{Duration of infertility}

Our study revealed $62 \%$ patients with duration of infertility between 1- 4 years indicating the level of awareness among the general population. 
Combined laparoscopy and hysteroscopy revealed 13\% normal laparoscopic findings, $22 \%$ ovarian factors, $32 \%$ endometriosis, $11 \%$ Pelvic tuberculosis, $16 \%$ uterine anomaly and 6\% tubal pathology (Figure 1).

Table 1: Distribution of cases according to type of infertility.

\begin{tabular}{|lll|}
$\begin{array}{l}\text { Type of } \\
\text { Infertility }\end{array}$ & Number of cases & $\begin{array}{l}\text { Percentage } \\
\text { of cases } \\
(\%)\end{array}$ \\
\hline Primary & 46 & 73 \\
\hline Secondary & 17 & 24 \\
\hline Total & 63 & 100 \\
\hline
\end{tabular}

Table 2: Age distributions in primary and secondary infertility cases.

\begin{tabular}{|c|c|c|c|c|c|c|}
\hline $\begin{array}{l}\text { Age } \\
\text { group } \\
\text { (in } \\
\text { Years) }\end{array}$ & $\begin{array}{l}\text { No. of } \\
\text { primary } \\
\text { infertility }\end{array}$ & $\%$ & $\begin{array}{l}\text { No. of } \\
\text { secondary } \\
\text { infertility }\end{array}$ & $\%$ & Total & $\%$ \\
\hline $20-25$ & 23 & $37 \%$ & 3 & $5 \%$ & 26 & $42 \%$ \\
\hline $26-30$ & 16 & $25 \%$ & 8 & $13 \%$ & 24 & $38 \%$ \\
\hline 31-35 & 3 & $5 \%$ & 4 & $6 \%$ & 7 & $11 \%$ \\
\hline$>35$ & 4 & $6 \%$ & 2 & $3 \%$ & 5 & $9 \%$ \\
\hline Total & 46 & $73 \%$ & 17 & $27 \%$ & 63 & $100 \%$ \\
\hline
\end{tabular}

\section{Type of infertility}

In our study simultaneous laparoscopy and hysteroscopy was done and it was observed that in the primary infertility group $33 \%$ had endometriosis, $26 \%$ of PCO and ovarian cyst, $11 \%$ with pelvic tuberculosis, $7 \%$ of uterine anomaly, $4 \%$ with tubal block and cervical stenosis, $2 \%$ with submucous fibroid, $13 \%$ were with normal findings.

Similarly in the secondary infertility group $29 \%$ had endometriosis, $12 \%$ of PCO, pelvic tuberculosis and tubal factors $0.6 \%$ each of uterine anomaly, fibroid, cervical stenosis and Asherman's syndrome was observed. 11\% had normal findings. This shows that endometriosis was a cause of infertility in both the groups and together endometriosis was the causative agent in $32 \%$.

\section{Uterine/Pelvic factor}

A total of 28 patients with uterine factors were observed in the present study and were divided into primary and secondary infertility group. In primary infertility group $36 \%$ showed endometriosis, 28\% had adhesions or pelvic tuberculosis, $7 \%$ with cervical stenosis, 1 case $3.5 \%$ with submucous fibroid. While in secondary infertility group $14 \%$ showed endometriosis, $11 \%$ had adhesions, $3.5 \%$ each of submucous fibroid, cervical stenosis and septate uterus.

\section{The ovarian factor}

The ovarian factors in primary and secondary infertility group were studied and a total of 17 cases had abnormal findings. Since chocolate cyst involves abnormal ovarian findings it has been considered in this group. In the primary infertility group 50\% showed PCO, $15 \%$ had B/L chocolate cyst, $10 \%$ showed U/L chocolate cyst, $5 \%$ each of ovarian cyst and dermoid cyst. In the secondary infertility group $10 \%$ had PCO and $5 \%$ had B/L chocolate cyst.

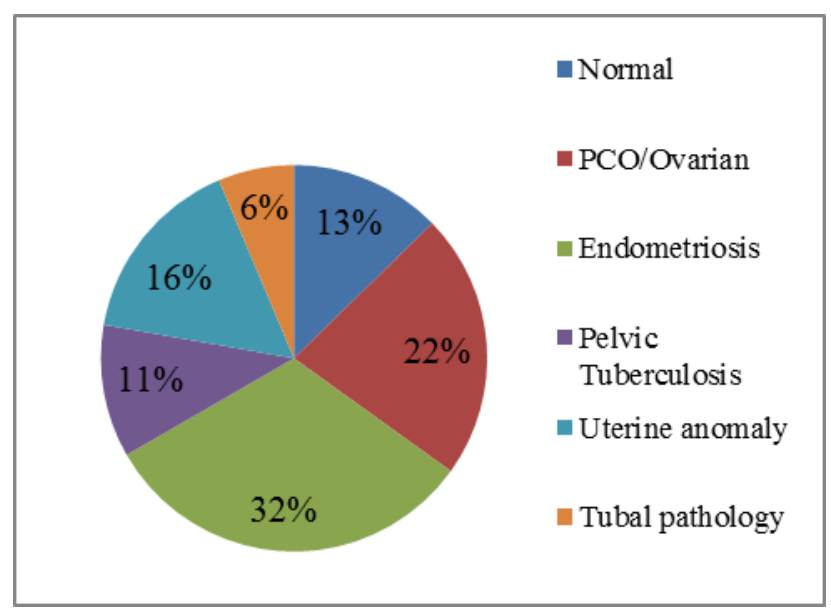

Figure 1: Laparohysteroscopy findings in the study population. 


\section{Tubal patency}

Tubal patency test was done by injection of methylene blue dye through the cervix and visualization of spillage of dye in the peritoneal cavity. Chromopertubation in primary and secondary infertility group was done and in primary infertility group it was observed that $48 \%$ had $\mathrm{B} / \mathrm{L}$ patent tubes, $11 \%$ had $\mathrm{B} / \mathrm{L}$ tubal block. $5 \%$ each of $\mathrm{B} / \mathrm{L}$ delayed spill, unilateral block and unilateral delayed spill.

In the secondary infertility group $12 \%$ had $\mathrm{B} / \mathrm{L}$ patent tubes, $6 \%$ showed $\mathrm{B} / \mathrm{L}$ delayed spill, $5 \%$ showed $\mathrm{B} / \mathrm{L}$ tubal block and $1.5 \%$ each of fimbrial block and unilateral delayed spill.

The Hysteroscopic findings in the present study in the primary infertility showed $5 \%$ intrauterine synechiae, 1.5 $\%$ of submucous fibroid, $3 \%$ of cervical stenosis, $5 \%$ of abnormal uterine cavity, $1.5 \%$ of ostial block while $57 \%$ had normal hysteroscopic findings. In secondary infertility group there were $5 \%$ of intrauterine synechiae, $1.5 \%$ each of submucous fibroid, cervical stenosis, Septate Uterus and ostial block and 7\% had normal findings. Hysteroscopy helped in detection of $26 \%$ cases with intrauterine abnormality in both the primary as well as secondary infertility group.

In our study there were 36 cases (78\%) with abnormal laparoscopic findings and normal hysteroscopic findings, 6 cases $(13 \%)$ with abnormal hysteroscopy and normal laparoscopy findings and 4 cases (9\%) with Abnormal laparohysteroscopic findings in the Primary infertility group (Figure 2).

In secondary infertility group there were 59\% with positive laparoscopic and normal hysteroscopic findings, $11 \%$ with abnormal laparohysteroscopic findings, $24 \%$ with abnormal hysteroscopy and normal laparoscopy and $6 \%$ of normal laparohysteroscopic findings (Figure 3).

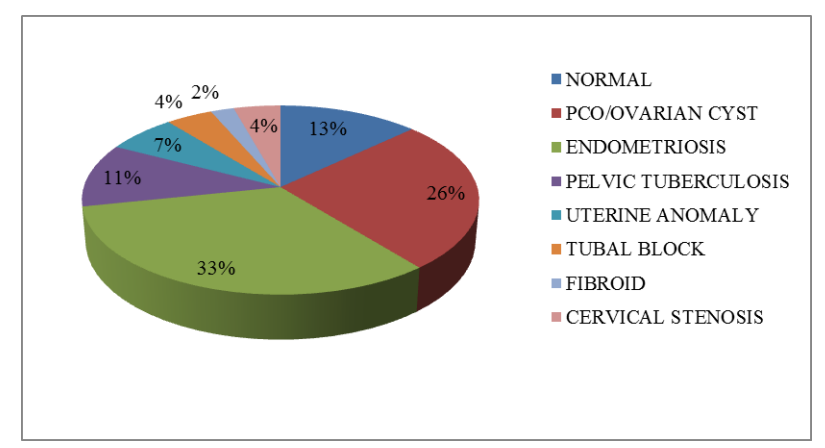

Figure 2: Laparohysteroscopic findings in primary infertility.

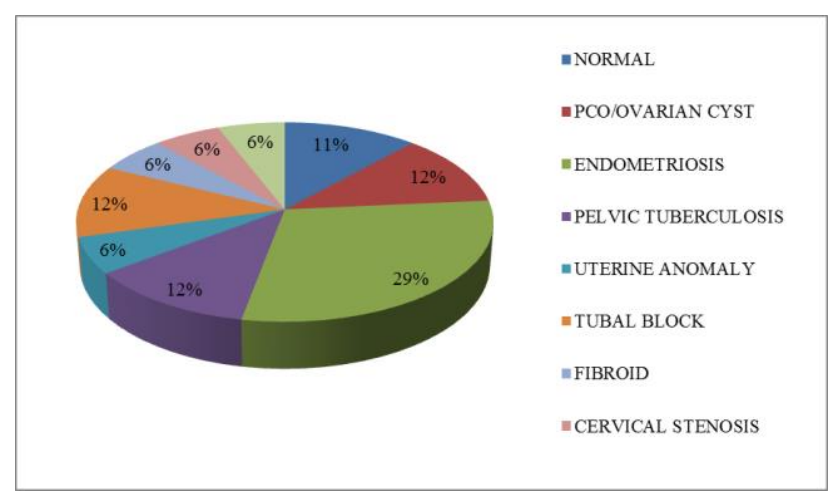

Figure 3: Laparohysteroscopic findings in secondary infertility.

\section{DISCUSSION}

Infertility is defined as failure to achieve pregnancy within a year of regular unprotected intercourse. Intracavitary pathology includes submucous leiomyomas and endometrial polyps, uterine septum, bicornuate uterus. Those pathologies often result in abnormal uterine bleeding, infertility or both. Congenital anomalies of the female reproductive system are associated with higher rate of infertility. Diagnostic laparohysteroscopy offers a reliable evaluation of the pelvic cavity and intrauterine and subsequent detection of diseased state.

Incidence of uterine congenital anomalies is not accurately known. Discrepancy is a result of inaccurate diagnostic methods, lack of uniform system of classification and many of them are asymptomatic. Mean prevalence of uterine malformation in general population and in the population of fertile women is approximately $4.3 \%$, in infertile patients approximately $3.5 \%$ and in patients with recurrent pregnancy losses approximately $13 \%$. $^{11}$ The incidence of uterine anomaly is $7.6 \% .^{12}$

In our study out of 63 cases studied, 47 cases (74\%) had normal findings while 8 cases $(13 \%)$ had normal findings. Diagnostic laparoscopy is the standard means of diagnosing the tubal pathology, peritoneal factors, endometriosis and intra-abdominal causes of infertility. ${ }^{13}$

Hysterolaparoscopy may appear to be invasive, but it may become more beneficial, as diagnosis and therapeutic interventions can be done at the same seating. The decisions for artificial reproductive technique (ART) can be taken in time after the evaluation of hysterolaparoscopy. ${ }^{14}$ Mettler reported that the complication rate of hysteroscopy was $1.65 \%{ }^{15}$ monitored by laparoscopy, the complication rate of hysteroscopy declined significantly. Hysterolaparoscopy is a very safe operation. Other than mild abdominal pain, there were no major surgical or anaesthetic complications in any of our patients. 
Pelvic inflammatory disease and endometriosis are still the two major lesions found among infertility women in more than $90 \%$. Out of 63 cases of infertility evaluated, primary infertility were $46(73 \%)$ and secondary infertility were 17 (27\%), which was in comparison with study group of Boricha YG et al., where primary infertility were $35(70 \%)$ and secondary infertility were $15(30 \%)$ of 50 patients studied. ${ }^{23}$ While in the study by Nayak $\mathrm{PK}^{26} 69 \%$ cases were of primary and $31 \%$ of secondary infertility.

The mean age of cases of infertility in the present study was 26.6 years which was comparable to the study by Waseem Talib et al. this suggests that the patients are aware of their problems and are willing to undergo treatment for the same. ${ }^{16}$ In a study by Wallace WHB et al. in terms of ovarian reserve, a typical woman has $12 \%$ of her reserve at age 30 and has only $3 \%$ at age $40 .{ }^{17} 81 \%$ of variation in ovarian reserve is due to age alone making age the most important factor in female infertility. ${ }^{17}$ The $\mathrm{p}$ value in the present study for age distribution amongst primary and secondary infertility is 0.02 which is statistically significant. Therefor there is a definite variation in occurrence of primary and secondary infertility depending upon the age of the patient.

Female age is the single most important determinant of spontaneous as well as treatment-related conception, with a gradual decline in fertility especially after the age of 35 years. ${ }^{18,19}$ Demographic studies have shown that more women are delaying childbearing at the present time than previously. ${ }^{20}$ This trend is expected to cause a corresponding rise in the mean age at which women first present with infertility. It is unclear as to whether women who present to fertility clinics at an older age have a different diagnostic profile from that in younger women. In particular, it has been suggested that older women may be more likely to be diagnosed with unexplained infertility and that this is due to the negative effect of age on ovarian reserve. ${ }^{21}$ But in the present study the age group of patients with infertility was found to be more in the younger age group of 21-25 yrs. which may indicate a trend towards decreasing age of occurrence of infertility.

In the present study the most common age group was b/w 21 to 25 years $(41 \%)$ and amongst them $36 . \%$ were of primary infertility and 5\% were of secondary infertility, studies by Boricha YG et al. ${ }^{23}$, Sortey KD et al., Sharma et al. $^{21}$ primary infertility was prevalent between the age group of 21 to 25 years, 42.85 . In $62 \%$ cases, the duration of infertility was from 1 to 4 years with primary infertility $51 \%$ and secondary infertility were $11 \%$. In the study by BorichaYG et al. maximum in cases the duration of infertility was between 4 to 7 years, in both primary infertility $54.28 \%$ and secondary infertility group $43 \%$ respectively. ${ }^{23}$

A study conducted by Fuentes A et al. concluded that after 8 years of marriage about one out of 25 women are infertile $(4.01 \%)$. This identified a group of patients that would benefit from a programme of assisted reproductive technology. ${ }^{24}$ Considering the low age group of infertility in our study and less duration of marriage it can be inferred that there is awareness amongst the study population regarding infertility and are willing to undergo treatment for the same. On the other hand it is a serious matter as the age of infertility might be declining with rising trend of endometriosis and PCO.

Anomalies of the uterus are considered to be one of the reasons for infertility in women, and for this reason diagnostic hysteroscopy is fundamental in screening for infertility. ${ }^{12}$ With the view of the low complication rates, minimal time requirement and a negligible effect on the post-operative course hysteroscopy could be performed on all infertile patients undergoing diagnostic laparoscopy. Intrauterine synechiae were the most frequent abnormal findings in patients evaluated for infertility. Patients with a history of dilatation and curettage and infertility should be submitted to hysteroscopy in order to rule out intrauterine synechiae as a possible cause of infertility. ${ }^{25}$

Polyps and submucosal fibroids can be definitively diagnosed and effectively treated with hysteroscopy. Diagnosis of endometrial polyps via hysteroscopy is $94 \%$ sensitive and $92 \%$ specific. For submucous myomas diagnostic hysteroscopy is $87 \%$ sensitive and $95 \%$ specific. $^{277}$

$75 \%$ had normal hysteroscopic findings which was similar to the study by Shakya et al. (88\%), while in our study $5 \%$ had submucous fibroid which was comparable to the studies by Shakya et al.(2\%), Lasmar et al. $(4.9 \%)^{25}$ and Nayak PK et al. $(3 \%)^{26}$ in the present study $3 \%$ had cervical stenosis which was similar to the study of Lasmar et al. $(2.2 \%)^{25}$, while $14 \%$ had septate uterus in comparison with Nayak PK et al. ${ }^{26}$ in which presence of septate uterus/ uterine anomalies was $10 \%$.

The study revealed ovarian pathology of $26 \%$ of primary infertility, comparable to the studies by Talib W et al. $(28 \%)^{16}$ and Usmani et al. (33\%).

Ovarian factors contribute to $22.2 \%$ in our study. This correlates with the study done by Aziz $\mathrm{N}$ et al. (21\%) and Chakraborti et al. (19.4\%). ${ }^{28}$ Of the total ovarian causes, PCOS was seen $15.6 \%$ and $11.4 \%$ in the studies by in Aziz $\mathrm{N}$ et al \& Chakraborti et al. ${ }^{28}$ and $19 \%$ in our study which suggests that laparoscopy should be done for these patients as PCOS can be diagnosed as well as treated by laparoscopy.

Tubal and peritoneal pathology are among the most common infertility causes, with infertility being seen in approximately $30-35 \%$ of couples. ${ }^{29}$ The study by Chakraborti et al. ${ }^{28}$ show bilateral tubal block to be the common tubal cause of Infertility. Our study also shows that $\mathrm{B} / \mathrm{L}$ block to be the commonest cause $(14.2 \%)$ of infertility due to tubal factor. In our study tubal factor was responsible for $22 \%$ of the infertility which correlates with other studies by Chakraborti et al. 
$(22.7 \%)^{28}$ and Goynumer $\mathrm{G}$ et al. $(24 \%) .^{30}$ It indicates that tubal block still plays a major role in the aetiology of infertility and evaluation by laparoscopy along with chromopertubation will give a better idea regarding the cause and appropriate management of the condition. Tubal disease is a common factor responsible for infertility and diagnostic laparoscopy is a valuable technique for complete assessment of female infertility and making treatment decisions according to the cause. ${ }^{31}$

In our study the incidence of endometriosis was $32 \%$, which is in corroboration by the recent study by Zhang $\mathrm{E}$ et al. This indicates a rise in the rate of endometriosis as compared to the earlier studies by Godinjak $\mathrm{Z}$ et al. (14\% and Parveen $S$ et al. $^{13}(8 \%)$ The high rate of endometriosis in our study may indicate an increase rise in the rate of detection of endometriosis which is basically a laparoscopic diagnosis, and hence there is requirement of laparohysteroscopic evaluation as well as treatment if required in cases of infertility. Among women with endometriosis, up to $30 \%$ to $50 \%$ may experience infertility. ${ }^{32}$ Pelvic tuberculosis was seen in 11 $\%$ of cases which was comparable to the study by Sharma et al $(10.6 \%)$ and Chakraborti et al. $(8.3 \%)^{28}$ which indicates that $\mathrm{TB}$ still contributes significantly to the aetiology of Infertility. The prevalence of endometriosis in women undergoing laparoscopy for evaluation of infertility is $9-50 \%$. $^{33}$

In our study $13 \%$ had normal laparohysteroscopic findings, while abnormal findings as diagnosed by laparoscopy and hysteroscopy together were $87 \%$. Diagnostic laparoscopy is the standard means of diagnosing the tubal pathology, peritoneal factors, endometriosis and intra-abdominal causes of infertility. Laparoscopy often reveals pelvic pathology as endometriosis, PCOD, pelvic and periadenexal adhesions that result in change of treatment. Thus diagnostic hystero-laparoscopy must be a part of an infertility work up in primary and secondary infertility.

In a study by Shokeir TA et al. ${ }^{34}$ in 2004, 612 consecutive infertile women underwent complete fertility evaluation at a tertiary university infertility clinic: 300 complained of primary infertility, 221 of secondary infertility, and 91 were requesting reversal of a previous tubal ligation. Laparoscopy was successful in 608 and hysteroscopy in 597 patients. The most frequent pathologies detected hysteroscopically in the infertile group were adhesive in nature and believed to be post-traumatic. The number of intrauterine abnormalities found by hysteroscopy was significantly greater than by hysterosalpingography. The rate of diagnosis of significant lesions by laparoscopy of $64.3 \%$ rose to $76.6 \%$ when the hysteroscopic findings were included. A significant number of women with secondary infertility had abnormal hysteroscopic findings when compared to either women with primary infertility or those requesting sterilization reversals. Hysteroscopic evaluation of the region of utero-tubal junction revealed significant lesions believed to have caused infertility in comparison with those requesting sterilization reversals.
The combined diagnostic approach of laparoscopy and hysteroscopy is recommended in the evaluation of female infertility in communities where the risk of pelvic infections is great.

\section{CONCLUSIONS}

Endometriosis was the leading cause of infertility (32\%) found on diagnostic laparoscopy which indicates a rising trend in detection or the occurrence of Endometriosis even in rural area.

Ovulatory disorder was also a major contributor (22\%) for infertility and thus diagnostic laparoscopy is required for diagnosis or the treatment.Intra uterine synechiae and cervical stenosis together led to $14 \%$ of cases of infertility and required surgical intervention; hence diagnostic as well as operative hysteroscopy is required for diagnosis as well as treatment of infertility. Laparoscopy combined with chromopertubation is able to diagnose tubal block $(6 \%)$ as well as tubal pathology indicated by delayed spill of dye (18\%). Combined with hysteroscopy it helps in diagnosis of fimbrial block. Laparoscopy detects pelvic pathology which can appear to be normal on other imaging modalities as it provides direct visualisation of the diseased condition and also an opportunity to treat the same if surgical intervention is required.

Though laparoscopy and hysteroscopy are invasive procedure the complications associated with them can be minimized with proper training and hence benefit the patients and gives us a direct view of the pathology.Both laparoscopy and hysteroscopy combined together is a valuable technique for complete assessment of female factors of infertility especially in an symptomatic patient and should be used early in the diagnostic work up. In a rural set up like ours where maximum patients belong to lower socioeconomic group laparohysteroscopic evaluation offers both diagnostic as well as therapeutic advantage.

\section{Funding: No funding sources Conflict of interest: None declared \\ Ethical approval: The study was approved by the Institutional Ethics Committee}

\section{REFERENCES}

1. Aral SO, Cates W Jr. The increasing concern with infertility. Why now? JAMA. 1983;250(17):2327-31.

2. Shaw W, Howkins J, Bourne GL. Shaw's textbook of gynaecology. Churchill Livingstone;1971.

3. International Committee for Monitoring Assisted Reproductive Technology (ICMART) and the World Health Organization (WHO) revised glossary of ART terminology, 2009* F. Zegers-Hochschild,a G. D. Adamson,b J. de Mouzon,c O. Ishihara,d R. Mansour,e K. Nygren,f E. Sullivan,g and S. Vanderpoel,h for ICMART and WHO Fertility and 
Sterilit Vol. 92, No. 5, November 20090015 0282/09.

4. Laparoscopy and Hysteroscopy, A guide for Patients, ASRM, 2012.

5. Saunders RD, Shwayder JM, Nakajima ST. Current methods of tubal patency assessment. Fertility and Sterility. 95(7):2171-9.

6. National Institute for Health and Clinical Excellence: Fertility: assessment and treatment for people with fertility problems. Nice clinical guideline 1562013.

7. Saunders RD, Shwayder JM, Nakajima ST. Current methods of tubal patency assessment. Fertil Steril. 2011;95(7):2171-9.

8. Mol BW, Collins JA, Burrows EA, van der Veen F, Bossuyt PM. Comparison of hysterosalpingography and laparoscopy in predicting fertility outcome. Hum Reprod. 1999;14(5):1237-42.

9. Sharma S, Mittal S, Aggarwal P. Management of infertility in low resource countries. Bjog. 2009;116 Suppl 1:77-83.

10. Widge A, Cleland J. The public sector's role in infertility management in India. Health Policy Plan. 2009;24(2):108-15.

11. Grimbizis GF, Camus M, Tarlatzis BC, Bontis JN, Devroey P. Clinical implications of uterine malformations and hysteroscopic treatment results. Hum Reprod Update. 2001;7(2):161-74.

12. Brusco GF, Arena S, Angelini A. The role of diagnostic hysteroscopy in infertile women. Minerva Ginecol. 2001;53(5):313-9.

13. Parveen S, Khanam M. Role of combined diagnostic laparoscopy and simultaneous diagnostic hysteroscopy for evaluation of female subfertility factors. Journal of surgery Pakistan (International) 2010;15(1):44-47.

14. Vaid K, Mehra S, Verma M, Jain S, Sharma A, Bhaskaran S. Pan endoscopic approach "hysterolaparoscopy" as an initial procedure in selected infertile women. J Clin Diagn Res. 2014;8(2):95-8.

15. Mettler L, Wendland EM, Patel P, Caballero R, Schollmeyer T. Hysteroscopy: an analysis of 2-years experience. Jsls. 2002;6(3):195-7.

16. Talib W. Infertile female: laparoscopic evaluation. Professional Med J. 2007;14(4)562-6.

17. Wallace WH, Kelsey TW. Human ovarian reserve from conception to the menopause. PLoS One. 2010;5(1):e8772.

18. Menken J, Trussell J, Larsen U. Age and infertility. Science. 1986;233(4771):1389-94.

19. Templeton A, Morris JK, Parslow W. Factors that affect outcome of in-vitro fertilisation treatment. Lancet. 1996;348(9039):1402-6.

20. Botting B, Dunnell K. Trends in fertility and contraception in the last quarter of the 20th century. Popul Trends. 2000;(100):32-9.
21. Sharma R, Sharma V. The infertile women: a study of 120 cases. J Indian Med Assoc. 1991;89(2):31-2.

22. Gleicher N, Barad D. Unexplained infertility: does it really exist? Hum Reprod. 2006;21(8):1951-5.

23. Boricha Y.G., Sharma R.K. Laparoscopy in 50 infertile couples: Prospective study. International Journal Of Medical And Clinical Research. 2011;2(2):63-6.

24. Fuentes A, Devoto L. Infertility after 8 years of marriage: a pilot study. Hum Reprod. 1994;9(2):2738.

25. Lasmar RB, Barrozo PR, Parente RC, Lasmar BP, da Rosa DB, Penna IA, et al. [Hysteroscopic evaluation in patients with infertility]. Rev Bras Ginecol Obstet. 2010;32(8):393-7.

26. Nayak P, Mahapatra P, Mallick J, Swain S, Mitra S, Sahoo J. Role of diagnostic hystero-laparoscopy in the evaluation of infertility: A retrospective study of 300 patients. J Hum Reprod Sci 2013;6(1):32-4.

27. Haider G, Rani S, Talpur S, Zehra N, Munir A. Laparoscopic evaluation of female infertility Ayub Med Coll Abbottabad. 2010;22(1):136-8.

28. Sharma R, Sharma V. The infertile women: a study of 120 cases. J Indian Med Assoc. 1991;89(2):31-2

29. Miller JH, Weinberg RK, Canino NL, Klein NA, Soules MR. The pattern of infertility diagnoses in women of advanced reproductive age. Am J Obstet Gynecol. 1999;181(4):952-7.

30. Goynume G, Yetim G, Gokcen O, Karaaslan I, Wetherilt L, Durukan B. Hysterosalpingography, Laparoscopy or both in the diagnosis of tubal disease In infertility. World Journal of Laproscopic Surgery. 2008;1(2):23-6.

31. Naz T, Hassan L, Gulmeen, Nighat F, Sultan S. Laparoscopic evaluation in infertility. J Coll Physicians Surg Pak. 2009;19(11):704-7.

32. Endometriosis: Does It Cause Infertility?, Factsheet. American Society for Reproductive Medicine. Revised 2012.

33. Missmer SA, Hankinson SE, Spiegelman D, Barbieri RL, Marshall LM, Hunter DJ. Incidence of laparoscopically confirmed endometriosis by demographic, anthropometric, and lifestyle factors. Am J Epidemiol. 2004;160(8):784-96.

34. Shokeir TA, Shalan HM, El-Shafei MM. Combined diagnostic approach of laparoscopy and hysteroscopy in the evaluation of female infertility: results of 612 patients. J Obstet Gynaecol Res. 2004;30(1):9-14

DOI: $10.5455 / 2320-1770 . i j r \operatorname{cog} 20150407$

Cite this article as: Chimote A, Samal S,Hariharan

C, Angik R. Laparoscopy and hysteroscopy in

patients of infertility in a rural set up. Int J Reprod Contracept Obstet Gynecol 2015;4:322-8. 